\title{
Surface modification of Kevlar fibre fabric and its influence on the properties of Kevlar/epoxy composites
}

\author{
N RAMASAMY ${ }^{1}$, V ARUMUGAM ${ }^{1}$ and S RAJKUMAR ${ }^{2, *}$ \\ ${ }^{1}$ Department of Aerospace Engineering, Madras Institute of Technology (MIT), Anna University, Chennai 600044, India \\ ${ }^{2}$ Advanced Research School for Technology and Product Simulation, Central Institute of Plastics Engineering and \\ Technology (CIPET), Chennai 600032, India \\ *Author for correspondence (rajkumar.s@mail.utoronto.ca)
}

MS received 25 June 2018; accepted 8 February 2019; published online 27 May 2019

\begin{abstract}
The present study addresses the enhancement of interfacial interaction between Kevlar and epoxy through surface modification of Kevlar fabric using various chemical treatments. The chemically modified aramid surface was examined by Fourier transformed infrared spectroscopy, energy dispersive spectroscopy, scanning electron microscopy (SEM), dynamic mechanical analysis and wettability characteristics. The Kevlar/epoxy composites were prepared using the hand lay-up process. Furthermore, the influence of surface modification was validated through the mechanical characteristics of Kevlar/epoxy composites. The study reveals that the chemical treatment of the Kevlar surface increases the polar functional groups and improves the interfacial adhesion between fibre and epoxy. The surface energy, work of adhesion and performance of Kevlar composites were studied for treated and untreated fibres. The tensile and flexural moduli were increased up to $38 \%$ in treated Kevlar fibre compared with untreated fibre. It was observed from SEM analysis that adhesive failure bonds rely on chemical bonds at the interface of fibre matrix composites and cohesive failure at the fibre matrix was decreased.
\end{abstract}

Keywords. Surface treatment; interfacial adhesion; Kevlar fibre; composites; wettability.

\section{Introduction}

Aramid fibres have been frequently utilized for composite material fabrication due to their high thermal stability in addition to their high modulus, high strength, vibration damping and resistance to chemicals. However, aramid is poor in terms of the interfacial adhesion between the fibre and polymer matrix, although the surface properties are a key factor governing the performance of the composites. Therefore, many surface modifications have been attempted on aramid fibres to improve their adhesion to polymer matrices [1-3]. According to Maity et al effectiveness on fibre matrix interaction is an important factor to improve the mechanical properties of fibre-reinforced composites [4]. Karger-Kocsis et al have observed the development of polymers with the change of functional properties from structural polymers to interphases in composites [5]. The researchers have investigated several methods to improve interfacial adhesion between fibre and matrix-reinforced composites, where the functional surface properties of the aramid fibre can be modified through chemical or physical treatments, such as coupling agents and surface grafting, plasma treatment, $\gamma$-rays and ultrasound [6-22]. Fu et al have reported that the tensile strength and tensile modulus were increased for short Kevlar fibre through hydrolysed treatment via mixing of maleic anhydride (MA)graft-polypropylene as the reactive compatibilizer [23]. The various researchers have indicated that the fibre and matrix adhesion was improved by treating with alkaline $\mathrm{NaOH}$ solution in Kevlar fibre and bio fibres [24,25]. Kim et al have found that the single-lap adhesive strength was increased for the flame treated Kevlar fibre composite with $0.5 \mathrm{wt} \%$ $\gamma$-methacryloxypropyltrimethoxysilane ( $\gamma$-MPS) and $\gamma$-3amino propyltriethoxysilane $(\gamma$-APS), due to which the treatment improved the bonding between $\mathrm{C}=\mathrm{O}$ of $\gamma$-MPS and $-\mathrm{N}-\mathrm{H}$ of $\gamma$-APS [26]. Many researchers investigated that the Kevlar fibres were surface modified with $\gamma$-APS by the condensation reaction between $\mathrm{Si}-\mathrm{OH}$ on the Kevlar fabric surface and siloxane from the silane coupling agent to obtain an amine-functionalized Kevlar surface which enhance $46.7 \%$ interfacial shear strength (IFSS) of the poly-p-phenylenebenzimidazole-terephthalamide fibre/epoxy matrix $[10,27]$.

Liu et al have reported that the interfacial strength, wear strength and bending strength were improved in modified Kevlar/epoxy composites by treating with epoxy chloropropane (ECP) $[28,29]$. Mckelvey et al have indicated that the better dry crew resistance in cellulose fibre was achieved by treating with epichlorohydrin $(\mathrm{ECH})$ at $80^{\circ} \mathrm{C}$ after pretreatment with concentrated solutions of basic salts [30]. Many researchers have demonstrated that the thermal and mechanical properties such as fatigue strength, strain failure and storage modulus were greatly improved using nanoparticles in polymer composites [31-33]. Both single fibre strength 
and IFSS were enhanced by surface modification of Kevlar fibre using a $\mathrm{SiO}_{2}$ /shape-memory polyurethane hybrid [34]. The interfacial adhesion strength between the matrix and Kevlar fibre and interlaminar shear strength was significantly increased by promoting polar functional groups by treatment with phosphorus acid fictionalization [35-37].

The main focus on the present investigation is to enhance the interfacial adhesion of Kevlar fibre with the epoxy matrix by chemical treatments. The eight surface treatments were employed to introduce the reactive groups on the Kevlar fabric surfaces. Among the treatments used, three treatments (TE$\mathrm{P}$, TS-N and TC-P) were applied on the fibre surface after the pre-treatment to obtain the permanent hydrophilic Kevlar surface. The relationship between Kevlar surface fictionalization by various treatments and the surface morphology of Kevlar fibre, and the mechanical properties of unidirectional Kevlar fibre/epoxy composites were investigated. The novel contribution in this research is the better understanding of the pre-treatment approach with various treatments on the Kevlar fibre surface to enhance the matrix adhesion with the fibre surface.

\section{Experimental}

\subsection{Materials}

Kevlar 29 (E. I. Du Pont India Pvt Ltd) fibre in the form of fabric was used for surface modification and the same was used as reinforcement with the epoxy matrix. The areal weight of Kevlar fabric was $440 \mathrm{~g} \mathrm{~m}^{-2}$. Epoxy resin (Araldite LY 556) was used as the matrix and Hardener (Araldite HY 951) was used. $\gamma$-MPS, $\gamma$-APS, phosphoric acid (PA), $\mathrm{NaOH}$ and ECP (E0581), were used as surface modifiers and acetone was of analytical reagent grade. Nanosilicon carbide and MA were used as fillers, which were added in aqueous solution for surface treatment of Kevlar fibre.

\subsection{Methods}

2.2a Surface cleaning: The Kevlar fabric was immersed in acetone and toluene for $4 \mathrm{~h}$ in sequence, followed by washing with distilled water to remove the dust and impurities on the surface of Kevlar fibre. Then the fibre was dried in a vacuum oven at $110^{\circ} \mathrm{C}$ for $6 \mathrm{~h}$. The cleaning of fibre was carried out prior to all eight surface treatments (named TN, TA, TS, TE, TC, TE-P, TS-N and TC-P) and untreated (NT) Kevlar fibre.

2.2b NaOH treatment (TN treatment): The Kevlar-29 fibre was hydrolysed in $10 \mathrm{wt} \%$ aqueous $\mathrm{NaOH}$ solution at room temperature for $30 \mathrm{~min}$. Subsequently, the samples were thoroughly washed with distilled water and then dried at room temperature for $24 \mathrm{~h}$. Further, the samples were dried in a vacuum oven for $24 \mathrm{~h}$. Treated samples were named TN. The amide groups in Kevlar fibre are hydrolysed, resulting in the formation of pendant amine and carboxylate groups. The carboxylate group is in the form of a sodium salt [23-25].

2.2c Silane treatment: TA treatment: The acidic solution was prepared by mixing distilled water until to obtain a $\mathrm{pH}$ value of 5 at room temperature. Then, $1 \mathrm{wt} \% \gamma$-APS silane coupling agent was mixed with acidic solution with a magnetic stirrer at a speed of $600 \mathrm{rpm}$ until the silane acidic solution became transparent, after which the surface cleaned Kevlar fibre mat was immersed in this solution for 10 min at room temperature. Then, the Kevlar fabrics were dried at $110^{\circ} \mathrm{C}$ for $2 \mathrm{~h}$ in an oven to active $\mathrm{Si}-\mathrm{OH}$ on the surface from silanols to siloxanes. These samples were indicated by TA $[10,26,27]$.

TS treatment: To enhance the polar group in Kevlar fabric, $0.5 \mathrm{wt} \% \gamma$-APS and $0.5 \mathrm{wt} \% \gamma$-MPS coupling agents were used and mixed with the prepared acidic solution by using a magnetic stirrer. In this treatment, Kevlar fabrics were immersed for $10 \mathrm{~min}$ in a mixed solution.

$T S-N$ treatment: The above surface treatment procedure was followed for Kevlar fabric using this silane solution. The better adhesion to Kevlar fabric is achieved, when the Kevlar fabric is pre-treated with $5 \mathrm{wt} \% \mathrm{NaOH}$ solution for $30 \mathrm{~min}$ at room temperature. Furthermore, the surface treated with $1 \mathrm{wt} \% \gamma$-APS $/ \gamma$-MPS acidic solution for $10 \mathrm{~min}$ to promote adhesive bonding and interfacial interaction with the matrix. The samples were designated as TS-N [6-9,26].

TC treatment: For treatment, $0.5 \mathrm{wt} \%$ of nano- $\mathrm{SiO}_{2}$ were mixed with the prepared $1 \mathrm{wt} \% \gamma$-APS acidic silane solution, in which Kevlar fibre was immersed in the solution for $15 \mathrm{~min}$ at room temperature followed by drying of fibre in a vacuum oven [31-34].

TC-P treatment: In order to increase the interfacial shear strength of the fibre matrix composite, two-step treatment is followed. The first step was Kevlar fabric is pre-treated with $15 \mathrm{wt} \% \mathrm{PA}$ at $40^{\circ} \mathrm{C}$ for $2 \mathrm{~h}$ and the second step was with $0.5 \mathrm{wt} \%$ amino silane ( $\gamma$-APS) along with $0.25 \mathrm{wt} \%$ of nano$\mathrm{SiO}_{2}$ and $0.25 \mathrm{wt} \% \mathrm{MA}$. The addition of nano- $\mathrm{SiO}_{2}$ and MA with the coupling agent may improve the stress transfer within the filler particle in a weaker epoxy matrix. MA grafting polymers form covalent bonds on the surface of Kevlar and improve their surface hydrophilicity and adhesion strength $[6,10-12,38]$.

2.2d ECH treatment (TE treatment): In ECH grafting surface modification, the Kevlar fabric was initially immersed in a solution of $\mathrm{KOH}(1 \%)$ at room temperature for $2 \mathrm{~h}$, followed by washing with distilled water and dried for $48 \mathrm{~h}$ at room temperature. It is the initiator for grafting with ECP and hydrolyzation of the amino bond and -COOK groups were introduced onto the Kevlar fibre surface, after which Kevlar fibre was grafted in ECP at $80^{\circ} \mathrm{C}$ for $6 \mathrm{~h}$. During surface modification treatment, acetone was added with $\mathrm{ECH}$ to prevent the drastic reaction, then washed with distilled water and dried in a vacuum oven $[28,29]$. 
TE-P treatment: The above surface treatment procedure was followed after the pre-treatment of surface cleaned fabric with $15 \mathrm{wt} \% \mathrm{PA}$ at $40^{\circ} \mathrm{C}$ for $2 \mathrm{~h}$ followed by washing with distilled water and dried for 2 days at room temperature. The samples were designated as TE and TE-P, respectively [3437,39].

\subsection{Characterization and testing of composites}

Fourier transform infrared (FTIR) spectroscopy was carried out to qualitatively identify the constituents of Kevlar fibre and the nature of surface modification during chemical treatment. FTIR measurement was carried out using a attenuated total reflectance-FTIR spectrometer in the frequency range of 500$4000 \mathrm{~cm}^{-1}$. Energy dispersive X-ray (EDX) examinations of the Kevlar fibres were carried out using a ZEISS SIGMA field emission scanning electron microscope combined with an ultra-thin window EDX detector for qualitative elemental analysis. The surface morphology of the Kevlar epoxy composite was analysed by field emission scanning electron microscopy (FE-SEM). The viscoelastic properties of composites were analysed by a dynamic mechanical analyser (DMA) Q800 (Universal V4.5A TA Instruments). The composites were prepared by the hand lay method with constant pressure. The nominal weight fraction of fibre is 50\%. The samples were prepared in accordance with ASTM-D4065-01 with a size of the specimen as $70 \times 13 \times 1.5 \mathrm{~mm}$. The test was carried out at a vibrational frequency of $1 \mathrm{~Hz}$ in a temperature range of $20-120^{\circ} \mathrm{C}$ at a heating rate of $1^{\circ} \mathrm{C} \min ^{-1}$ and a strain amplitude of $0.50 \mathrm{~mm}$ throughout the experiment. Loss modulus, storage modulus and loss tangent were determined as a function of temperature. The tensile properties of the composites with treated and untreated fibres were measured using the universal testing machine (INSTRON 3382). The composite specimens were prepared as per ASTMD 3039/3039 M. Five good specimens on each category (surface treated and untreated) were subjected to tensile testing at a cross head speed of $2 \mathrm{~mm} \mathrm{~min}^{-1}$ at room temperature.

The composite specimens for flexural testing were prepared as per ASTM D 790-03. For each test, five samples were tested at room temperature and average data were taken as final results. The sample test data were collected and the flexural yield strength, flexural modulus and strain to failure were obtained. Flexural strength was evaluated on the samples using the universal testing machine with a cross head speed of $1.4 \mathrm{~mm} \mathrm{~min}^{-1}$ at a span to depth ratio of 32 . The three-point bending test is used to find the flexural modulus, flexural strength and strain to failure at break of the aramid fibre-reinforced polymer composites. The contact angle of the Kevlar surface was measured by a goniometer setup. In this technique, initially the videos are obtained from the setup and converted to images. These are further imported to computeraided design and drafting software which assists in drafting. This enables the measurement of the size accurately. The wettability, which is a contact angle dependent parameter, is measured in Kevlar fibre subjected to the epoxy matrix for various treatments.

\subsection{Surface free energy estimation}

The surface free energy of the modified Kevlar fibre surface mat is estimated, while epoxy resin is used for contact angle measurement. The Young's and Neumann's equations [40] are used to determine the surface free energy of the Kevlar surface.

$$
\gamma_{\mathrm{sv}}=\gamma_{\mathrm{s}}+\gamma_{1} \cos \theta
$$

where $\gamma_{1}$ is the surface free energy of the liquid interface, from Young's equation (1) two parameters are unknown, $\gamma_{\mathrm{sv}}$ is the surface free energy of the solid/liquid interface, $\gamma_{\mathrm{s}}$ is the surface free energy of the solid and $\theta$ is the contact angle in the Young's equation. Young's equation is solved by the Neumann concept in this section

$$
\gamma_{\mathrm{s}}=\frac{\left(\sqrt{\gamma_{\mathrm{sv}}}-\sqrt{\gamma_{1}}\right)^{2}}{1-0.015 \sqrt{\gamma_{\mathrm{sv}} \gamma_{1}}}
$$

From Neumann's equation, when the denominator tends to zero, the entire equation becomes infinity. To evaluate the surface free energy of the Kevlar fibre mat, substitute equation (2) in (1) to obtain (3)

$$
\gamma_{\mathrm{sv}}=\frac{\left(\sqrt{\gamma_{\mathrm{sv}}}-\sqrt{\gamma_{1}}\right)^{2}}{1-0.015 \sqrt{\gamma_{\mathrm{sv}} \gamma_{1}}}-\gamma_{1} \cos \theta=0 .
$$

The surface free energy of the surface can be estimated by using equation (3) and work of adhesion of the Kevlar surface was obtained with Young-Dupre equations substituted into Young's equation (4)

$$
\mathrm{WA}=\gamma_{1}(1+\cos \theta) \text {. }
$$

\section{Results and discussion}

\subsection{Chemical characterization of the Kevlar surface}

The IR spectrum of treated fibres is depicted in figure 1. The spectrum of TN samples shows $\mathrm{OH}$ stretching vibration between 3000 and $2500 \mathrm{~cm}^{-1}$. The peak at $818 \mathrm{~cm}^{-1}$ is an out-of-plane deformation vibration of the para-substituted aromatic rings. This peak is the characteristic of highly polar $-\mathrm{COOH}$ or $-\mathrm{COONa}$ substituents. The spectrum of the TA specimen after $\gamma$-APS treatment, the bending vibration of $\mathrm{OH}$ appeared at $3309 \mathrm{~cm}^{-1}$ and the $\mathrm{C}-\mathrm{N}$ peak at $1223 \mathrm{~cm}^{-1}$ indicated the successful hydrolysis of $\mathrm{Si}-\mathrm{OCH}_{2} \mathrm{CH}_{3}$ from $\gamma$-APS. FT-IR spectra was observed for the $\gamma$-MPS $/ \gamma$-APS silane coupling agent (TS samples) on the Kevlar fibre surface. The intense peak of $\mathrm{C}=\mathrm{O}$ at $1732 \mathrm{~cm}^{-1}$ was produced 


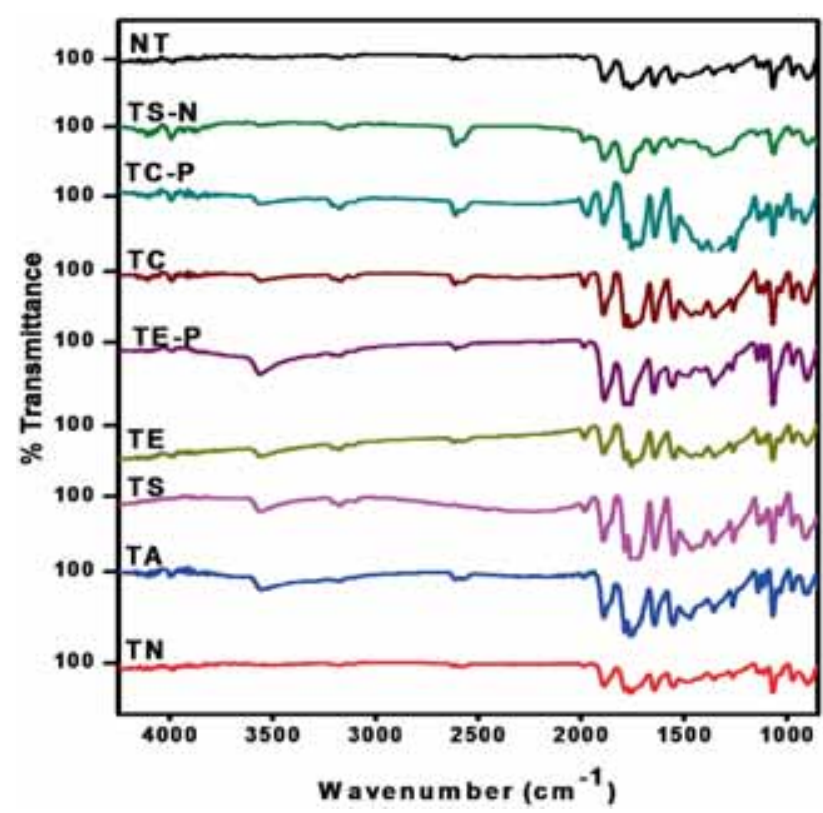

Figure 1. Chemical characterization of the Kevlar surface.

due to $\mathrm{C}=\mathrm{O}$ of $\gamma$-MPS and $-\mathrm{N}-\mathrm{H}$ of $\gamma$-APS. Two new peaks at 3311 and $1010 \mathrm{~cm}^{-1}$ appeared due to the $-\mathrm{OH}$ and $\mathrm{Si}-\mathrm{OH}$ stretching in silane treatment. The TS sample was pre-treated with $\mathrm{NaOH}$ and the treated sample (TS-N) has a strong peak of $\mathrm{C}=\mathrm{O}$ appearing at $1719 \mathrm{~cm}^{-1}$, which was decreased due to strong bonding ( $-\mathrm{CONH}-$ ) between $\gamma$-MPS and $\gamma$-APS. From the effect of alkaline free bridging-OH was produced at $3742 \mathrm{~cm}^{-1}$. The silane treatment after pre-treatment is an efficient treatment condition for improving the chemical adsorption of coupling agents on the Kevlar composite surface.

It can be seen that the $-\mathrm{OH}$ peak shifted to $3313 \mathrm{~cm}^{-1}$ after $0.5 \%$ nano- $\mathrm{SiO}_{2}$ was mixed with $\gamma$-APS solution. The spectrum (TC specimen) of nano- $\mathrm{SiO}_{2}$ exhibited the characteristic peaks at about $1105 \mathrm{~cm}^{-1}$, which is due to the asymmetric stretching vibrations of siloxane groups $(\mathrm{Si}-\mathrm{O}-\mathrm{Si})$, whereas the band at $817 \mathrm{~cm}^{-1}$ is attributed to the symmetric stretching of $\mathrm{Si}-\mathrm{O}-\mathrm{Si}$ as observed in [16]. The characteristic bands of PA pre-treatment (TC-P specimen) at 3314 and $1532 \mathrm{~cm}^{-1}$ are attributed to the $\mathrm{N}-\mathrm{H}$ vibration of the primary amine in the Kevlar surface. The pre-treated Kevlar fibre exhibited new peak at $3745 \mathrm{~cm}^{-1}$ which was free bridging -OH groups and $\mathrm{C}=\mathrm{O}$ groups shifted to a strong bond at $1738 \mathrm{~cm}^{-1}$ by the MA filler added in $\gamma$-APS solution. A significant increase of the active groups on the Kevlar fibre surface might lead to better adhesion between the fibre and matrix. The FTIR spectrum of the sample of TE had shown the peaks at $3312 \mathrm{~cm}^{-1}$ (-OH group), $1734 \mathrm{~cm}^{-1}(-\mathrm{C}=\mathrm{O}$ group) and $1641 \mathrm{~cm}^{-1}$ (-NH bending amine group). ECP-grafted Kevlar fibre has the epoxy peak at $2921 \mathrm{~cm}^{-1}$ whereas untreated fibre and other treated Kevlar fibre do not have this peak. The spectrum showed that the TE-P specimen with ECP chemical treatment after pre-treatment with PA had increased with peaks at $3740 \mathrm{~cm}^{-1}$ (free bridging $\mathrm{OH}$-groups). It may be

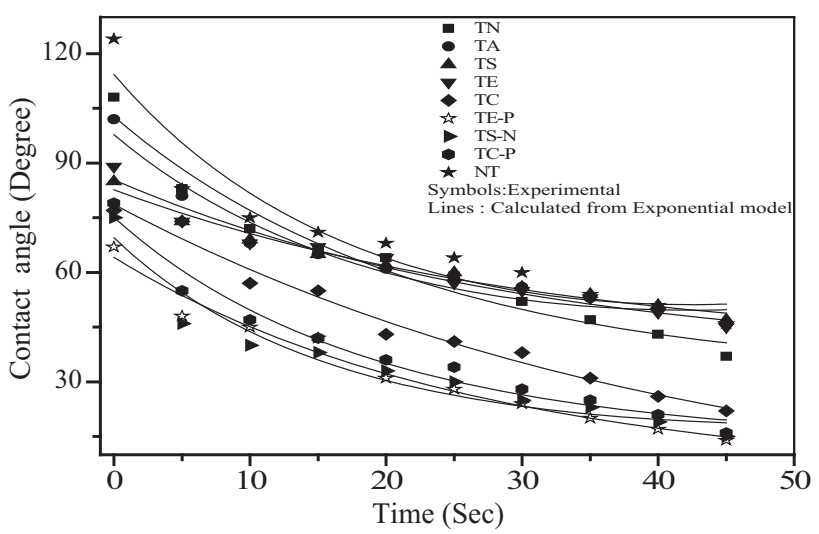

Figure 2. Contact angle of Kevlar fibre with time varying for different treatments.

assigned to non-acidic silanol groups, however untreated fibre does not have this peak. We confirm that the surface of Kevlar fibre is improved by pre-treated ECP surface-modified Kevlar fibre, which may result in increasing the interfacial adhesion between the Kevlar fibre and epoxy matrix.

\subsection{Wetting test analysis}

The wettability of Kevlar fibre is an influencing factor to enhance the interfacial adhesion of the Kevlar surface fibre mat with the epoxy matrix. From figure 2, it can be seen that the contact angle decreases with an increase in time duration to spreading of resin in the Kevlar fibre mat. The wetting of the Kevlar surface is inversely proportional to the contact angle measured. The wetting behaviours were improved in $\mathrm{NaOH}$ and phosphoric pre-surface treatment methods when compared to untreated and other treated Kevlar fibres. It is due to the fact that polar components on the Kevlar surfaces were increased by hydroxyl and carbonaxyl groups formed on surface treated Kevlar. The surface roughness can also have important effects on the wetting angle. The modified Kevlar surface roughness has more wetting ability with epoxy resin during impregnation.

The effects of the chemically modified Kevlar surface on the wetting behaviour are understood in detail, wherein an exponential model is employed, which is fitted with the experimental data:

$$
y=\mathrm{e}^{a+b x+c x^{2}}
$$

where $a, b$ and $c$ are the empirical constants which are determined by the best fit. The good understanding between the experimental data and the fits was observed. The values of the fit parameters with $95 \%$ confidence intervals, as well as the sum of the squared deviations is $\chi^{2}$ which is obtained from the best fit; $\chi^{2}$ value increases for treated fibres and reported maximum for ECP treated Kevlar fibres. 

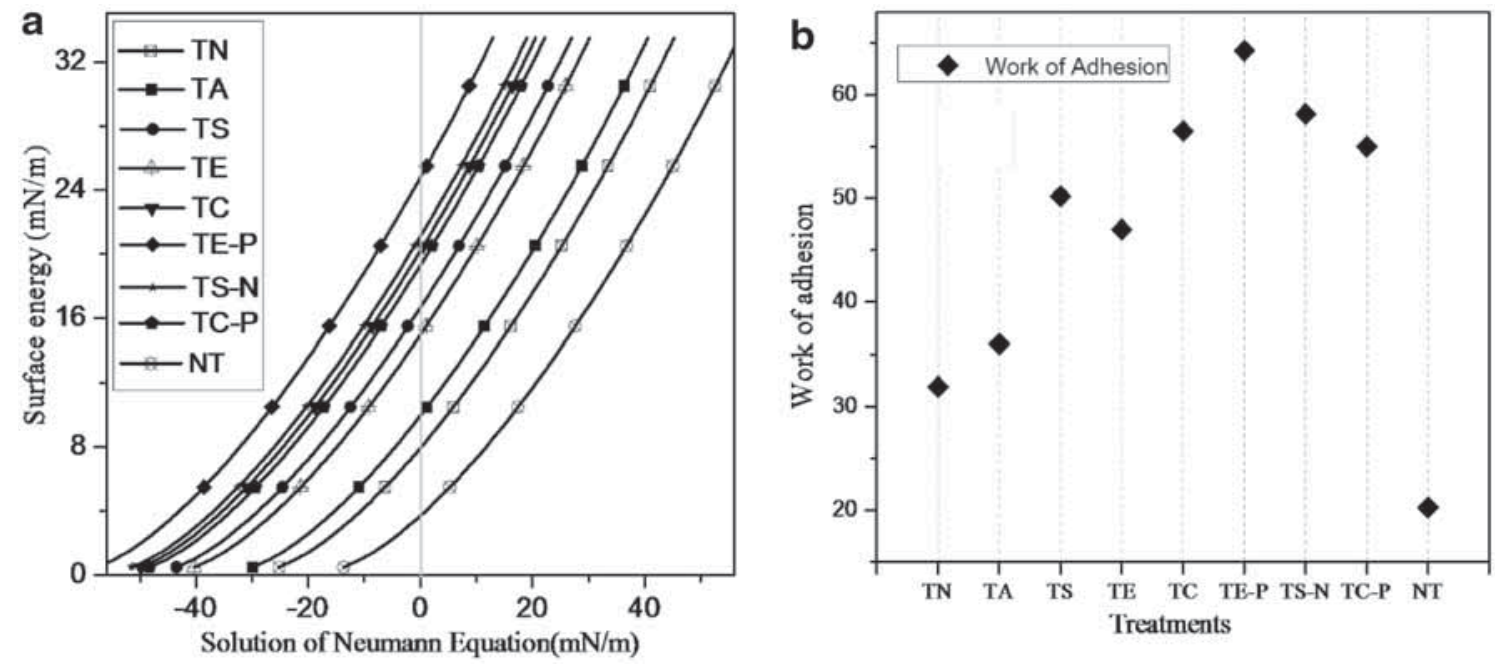

Figure 3. Surface free energy of Kevlar (a) with Neumann equation and (b) work of adhesion.

Table 1. Surface free energies of different treated samples.

\begin{tabular}{lrrrrrrrrc}
\hline Samples & TN & TA & TS & TE & TC & TE-P & TS-N & TC-P & NT \\
\hline$Y_{\mathrm{S}}\left(\mathrm{mN} \mathrm{m}^{-1}\right)$ & 7.9 & 9.95 & 16.7 & 15 & 20.2 & 24.8 & 21.1 & 19.3 & 3.7 \\
$W_{\mathrm{A}}\left(\mathrm{mN} \mathrm{m}^{-1}\right)$ & 31.9 & 36.59 & 50.2 & 47 & 56.5 & 64.25 & 58.16 & 55.01 & 20.36 \\
\hline
\end{tabular}

\subsection{Surface energy and work of adhesion determination}

The contact angle analysis is very useful to determine the surface energy of aramid fibres for various chemical treatments. Figure 3 a shows the surface energy values calculated using the Neumann equation (2) with assumed values of $\gamma_{\mathrm{s}}$. The accurate values of the surface energy were identified yielding zero in the Neumann equation. It was observed that the surface energy is found to be increasing, suggesting the increase in polar components after surface modifications [29]. Table 1 shows that the surface energy and work of adhesion were increased with a decrease in the contact angle due to adsorption of the electron pair on the chemically modified surfaces, which has promoted the polarity on the Kevlar surface.

The total surface energy of the Kevlar surface was improved up to $65 \%$ for TE-P pre-treatment and $26 \%$ for TS-N pretreatment when compared to other surface treatments. As observed in figure $3 \mathrm{~b}$, work of adhesion was improved for pretreatment methods compared with untreated fibre and other surface treatments. It can be found that stronger polarity of the Kevlar surface enhances the impregnation between polar epoxy resin and surface modified Kevlar.

\subsection{Elemental analysis}

The surface chemical composition of the treated Kevlar fibre was evaluated by EDX analysis [41]. Table 2 shows $\mathrm{C}, \mathrm{O}, \mathrm{N}$, $\mathrm{Si}$ and $\mathrm{O} / \mathrm{C}$ ratios after being surface modified by chemical treatments. The $\mathrm{O} / \mathrm{C}$ ratio was increased in addition to increase the oxygen element by $21 \%$ after the surface modification. The nitrogen element ratio is increased in $\mathrm{ECH}$ treated and silane treated Kevlar surfaces. The O/C ratio was improved by $15 \%$ in pre-treatment methods of treatment with other single step treatments. It is evident that desirable organic functional groups were occurred on the surface of Kevlar fibre by these treatments.

The polar surface is activated on the Kevlar surface which influences the improvement of adhesion between the matrix and fibre surface. The nitrogen intensity is higher in PA pretreated $\mathrm{ECH}$ treatment than those of the other treatments which also activated $\mathrm{N}-\mathrm{H}$ and $\mathrm{N}-\mathrm{C}$ on the Kevlar surface. The significance differences in chemical characterization in the modified Kevlar surface are adhered to enhance the fibre matrix composite interface. EDX analyses indicate that the successful treatment was achieved on the fibre surface.

\subsection{Tensile strength}

The tensile properties were obviously higher in treated Kevlar fibre than those of untreated fibre. It was attributed to modify the chemical structure of the fibre surface with the interlocking epoxy matrix. Figure 4 a shows the stress-strain curve of the treated and untreated fibre composites. The tensile forces were increased with an increase in deflection during testing. The tensile strength of TE-P, TS-N and TC-Pmodified Kevlar fibre surfaces was greatly improved by 5 and 
Table 2. EDX analysis of atomic concentrations of the Kevlar fibre surface.

\begin{tabular}{lcccccccc}
\hline Elements & $\mathrm{C}(\%)$ & $\mathrm{O}(\%)$ & $\mathrm{Si}(\%)$ & $\mathrm{Ca}(\%)$ & $\mathrm{N}(\%)$ & $\mathrm{S}(\%)$ & $\mathrm{Na}(\%)$ & $\mathrm{O} / \mathrm{C}$ \\
\hline NT & 84.49 & 14.80 & 0.03 & 0.06 & & 0.23 & 0.36 & 0.17 \\
TN & 83.04 & 16.51 & & & & 0.25 & 0.20 & 0.20 \\
TA & 72.66 & 17.96 & 0.34 & 0.22 & 8.24 & 0.22 & 0.36 & 0.25 \\
TE & 73.33 & 13.62 & & & 12.58 & 0.18 & 0.24 & 0.19 \\
TS & 81.20 & 17.46 & 0.21 & 0.65 & & 0.20 & 0.29 & 0.21 \\
TC & 83.66 & 15.74 & 0.03 & 0.07 & & 0.22 & 0.24 & 0.19 \\
TE-P & 72.61 & 13.25 & 0.01 & & 13.54 & 0.20 & 0.29 & 0.18 \\
TS-N & 81.05 & 17.99 & 0.45 & & & 0.16 & 0.29 & 0.22 \\
TC-P & 81.26 & 17.74 & 0.37 & 0.04 & & 0.19 & 0.15 & 0.22 \\
\hline
\end{tabular}
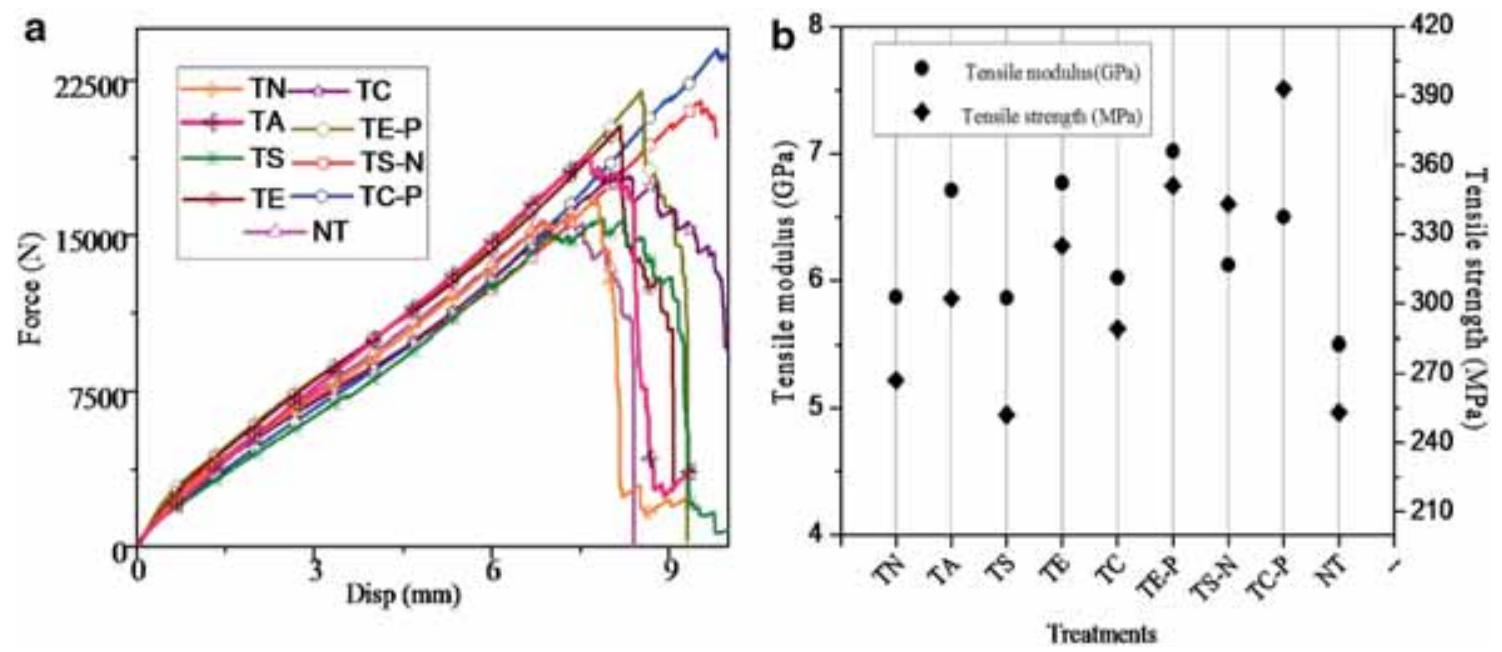

Figure 4. Tensile strength Kevlar composites (a) force-displacement curve and (b) tensile modulus.
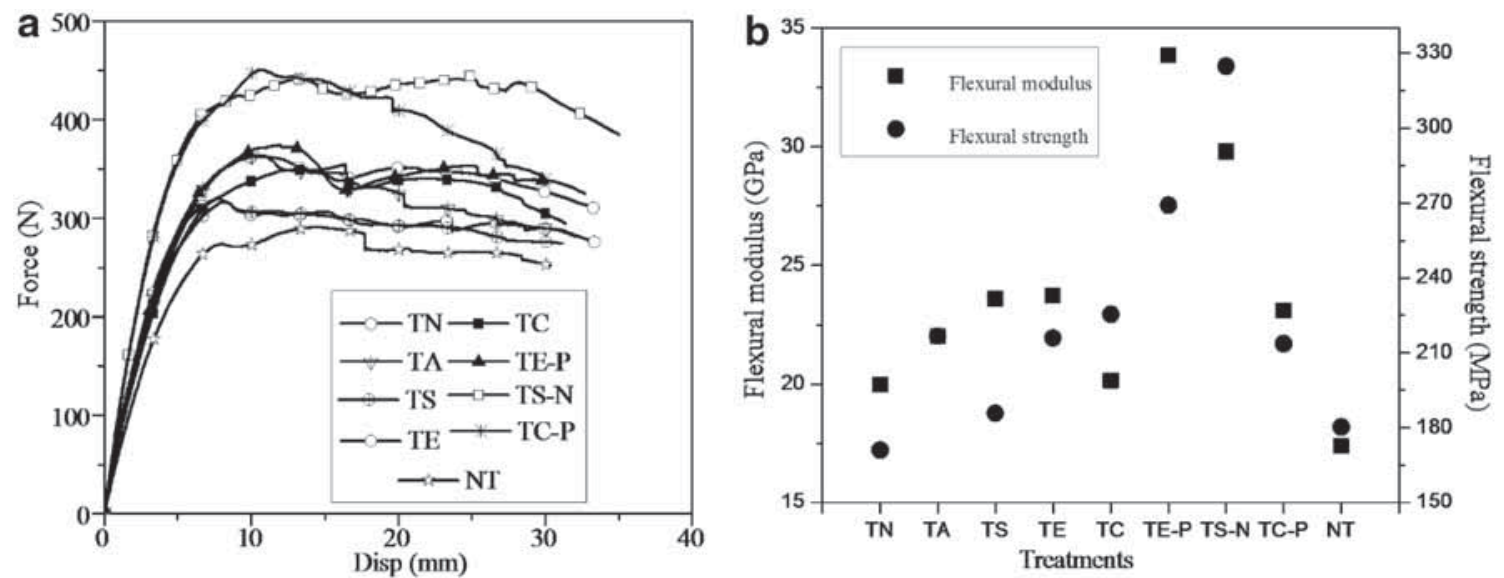

Figure 5. Flexural testing (a) force vs. displacement and (b) flexural modulus.

$55 \%$ when compared to non-pretreated surface and untreated surface, respectively. This may be attributed to hydroxyl groups and the amount of surface oxygen was high in the fibre surface and also polarity was increased in the Kevlar fibre surface, which lead to more interfacial adhesion between the matrix and Kevlar fibre. It was also demonstrated in figure $4 \mathrm{~b}$ that the tensile modulus was higher for TE-P samples compared to other treated samples due to improved adhesion polar 

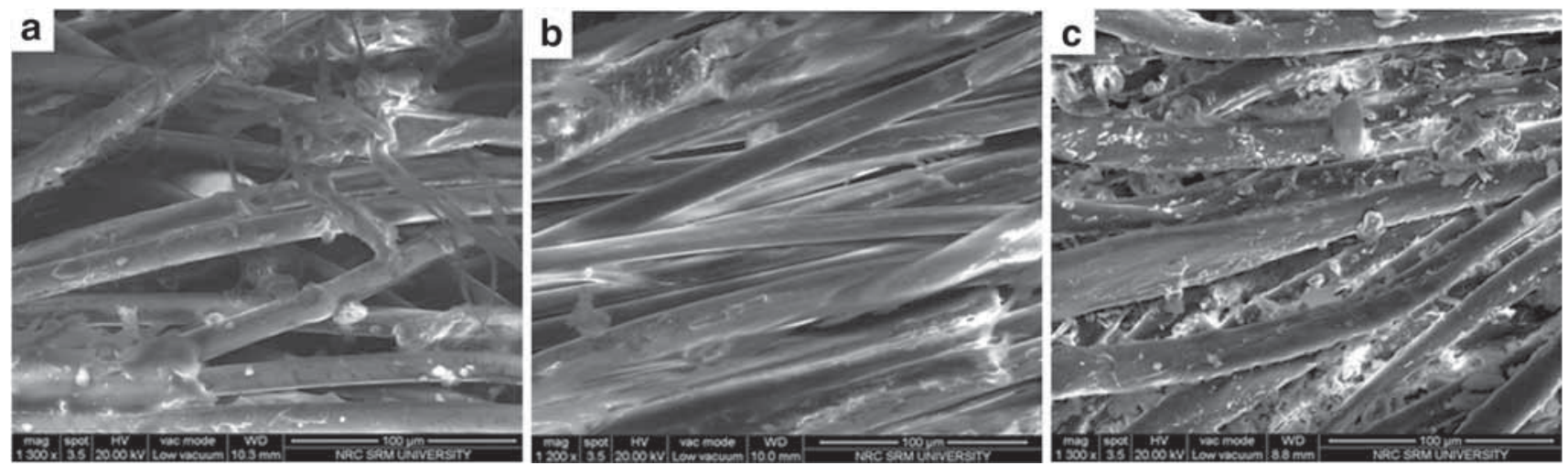

Figure 6. SEM image of the fractured Kevlar/epoxy composite (a) TE-P treatment, (b) TS-N treatment and (c) TC-P treatment.
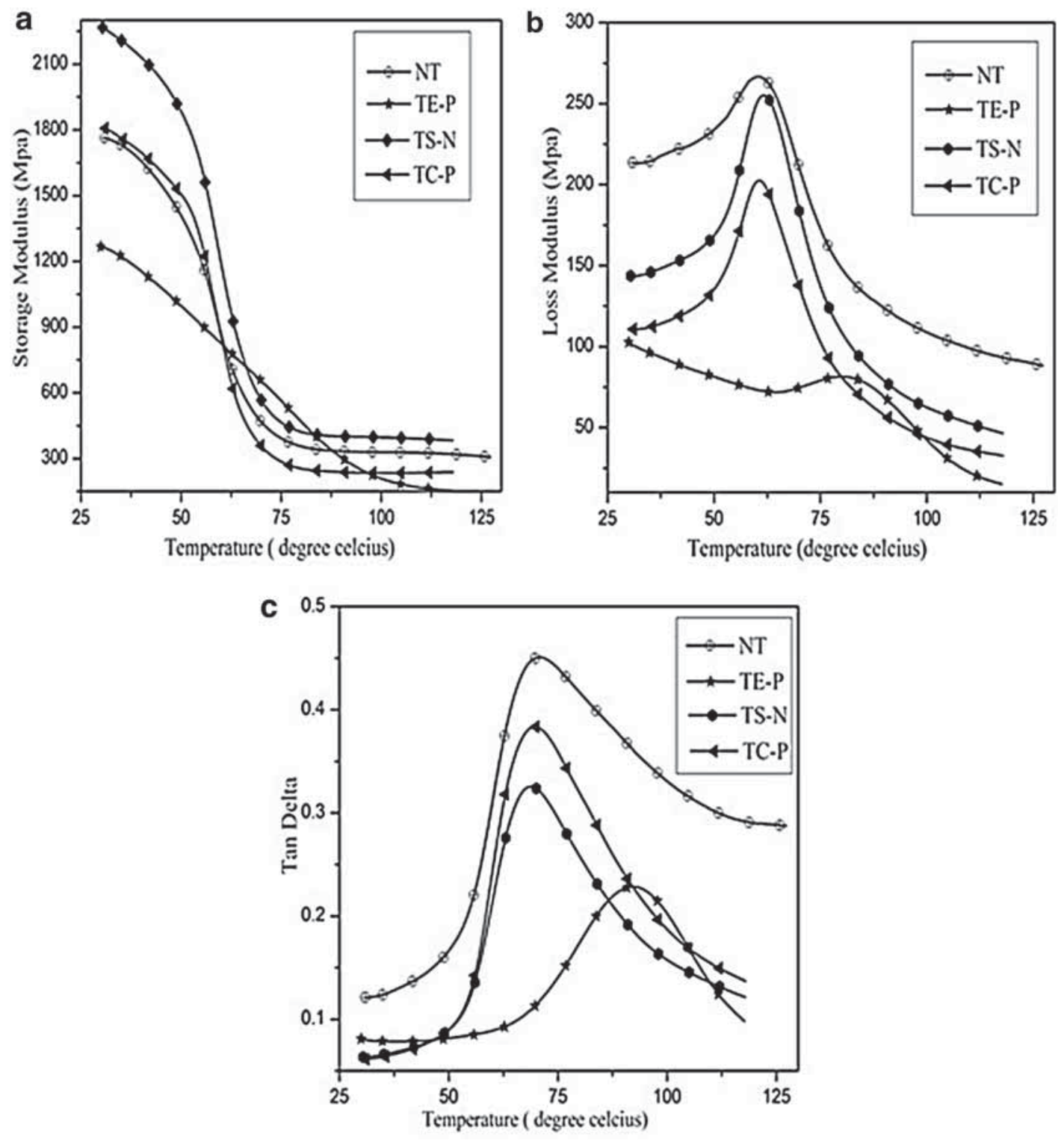

Figure 7. DMA with function of temperature (a) storage modulus, (b) loss modulus and (c) loss factor. 
bonding and also reduced cohesive failure in the epoxy matrix, which has been chemically bonding with Kevlar fibre.

\subsection{Flexural strength}

It was reported in figure $5 \mathrm{~b}$ that the TE-P and TS-N treated Kevlar surfaces have more flexural moduli of 33 and $29 \mathrm{GPa}$ as well as flexural strength of 269 and $324 \mathrm{MPa}$, respectively. The mechanical interlocking was greatly improved in between the fibre and matrix due to pre-treatment. In alkaline treated (TN) fibre, flexural strength was reduced, which may be due to the random change in the inter-molecular structure on the Kevlar surface, consequently the polarity of the surface was reduced. Strain at failure was increased in the silane treated Kevlar surface.

\subsection{SEM analysis}

The surface morphology of the tensile fractured Kevlar fibre composite was observed and shown in figure $6 a-c$. The SEM images indicate that the fibre matrix failure occurs interfacially by swelling of fibre during the treatment and subsequently, the de-bonding occurred in these regions. This produces a weak fibre/matrix interface and deterioration of the stress transfer from the matrix to the fibres, thus affecting the mechanical properties of the composites. It was evident in SEM images that cohesive fracture leads to interfacial adhesion which was attributed to improve the mechanical interlocking in between the matrix and Kevlar fibre by a new chemical treatment compared with other traditional treatments. Consequently resin was adhering more with chemically treated fibre due to which fracture energy was enhanced. Nano- $\mathrm{SiO}_{2}$ was dispersed in the matrix as indicated in figure $6 c$. The fibre matrix failure occurred due to matrix cracking and voids in the specimens. The results indicate that based on the mechanical properties of TE-P and TS-N-treated Kevlar fibre composites epoxy matrix has more wettability and interfacial adhesion as compared with other treatment methods.

\subsection{Viscoelastic properties}

The dynamic mechanical analysis (DMA) results can clearly show the stiffness or storage modulus, loss factor and loss modulus of surface treated Kevlar composite. Glass transition temperature $\left(T_{\mathrm{g}}\right)$ was evaluated from the loss tangent factor of the composite. Figure 7 a shows that stiffness of the treated Kevlar composite is proportional to energy stored and decreased with the change in temperature during cycle. The silane pre-treated (TS-N) Kevlar surface enhanced the storage modulus with an increase of greater reinforcement with the epoxy matrix. Figure $7 b$ and $c$ shows that the loss factor or dissipation factor and glass transition temperature are higher for TE-P treated Kevlar fibre compared to other treating mechanisms and untreated Kevlar fibres, which may arise as a result of cross-linking reactions at the molecular interface of Kevlar composites and increased intermolecular forces leading to reduced flexibility of the segment chain in the region of glass transition in composites [42].

Glass transition temperature $\left(T_{\mathrm{g}}\right)$ of the composites was evaluated from tangent loss as follows $T_{\mathrm{g}}=71.12^{\circ} \mathrm{C}, T_{\mathrm{g}}=$ $92.23^{\circ} \mathrm{C}, T_{\mathrm{g}}=68.88^{\circ} \mathrm{C}$ and $T_{\mathrm{g}}=69.78^{\circ} \mathrm{C}$ for the NT, TE-P, TS-N and TC-P treated Kevlar surface, respectively. The internal energy dissipated in Kevlar matrix composites mainly depends on degree of adhesion between the matrix and fibre surface when subjected to vibrational cyclic loading. The untreated and TC-P treated Kevlar fibre composites have a weaker bond which was reflected in a low storage modulus and loss factor due to poor adhesion [35] reported in figure $7 \mathrm{c}$.

\section{Conclusion}

Surface modification of the Kevlar fibre mat with various chemical treatments was achieved. FTIR analysis reveals the formation of binding sites like hydroxyl and carbonyl functional groups upon chemical treatment. The treated fibres exhibit the better formation of functional sites along the Kevlar surface. Further, elemental analysis on the surface suggests the increase in the $\mathrm{O} / \mathrm{C}$ ratio in $\mathrm{TA}$ treated fibre, which is also evident for the better surface modification. The treatments on Kevlar fibre have improved the tensile and flexural modulus by 49 and $42 \%$ respectively compared to the untreated fibre composite. Twenty-seven percent tensile modulus and $31 \%$ flexural modulus were enhanced in pre-treated Kevlar composites compared to untreated composites by improving the interfacial adhesion in fibre matrix composites, which was also shown in wetting analysis. This is due to the improvement in the interfacial locking between the fibre and matrix interface which enhances the polar component on the surface of Kevlar fabric. It was concluded that selected pre-treatment approaches in Kevlar fibre has improved adhesion mechanisms with the epoxy matrix, which was indicated in wetting analysis and element characterization. ECH treated Kevlar fibre after pre-treated with PA has attained the improved mechanical properties of $3.7 \%$ tensile modulus and $42.5 \%$ flexural modulus comparable to the non-pretreatment ECH surface modification process. Also, after the pre-treatment process, the surface energy was enhanced from 15 to $24.8 \mathrm{mN} \mathrm{m}^{-1}$ and is found to be $17.6 \%$ higher than the TS-N treated samples. It is concluded from DMA analysis that the interfacial adhesion mechanism is promoted in the TE-P and TS-N treated Kevlar fibre surface and glass transition temperature was reported higher in TE-P treated Kevlar composites. SEM micrographs also evident that the adhesion between the matrix and Kevlar fibre was improved significantly in TE-P treated Kevlar composites. 


\section{References}

[1] Mori M, Uyama Y and Ikadat Y 1994 Polymer 355336

[2] Tarantili P A and Andreopoulos A G 1997 J. Appl. Polym. Sci. 65267

[3] Li G, Zhang C, Wang Y, Li P, Yu Y et al 2008 Compos. Sci. Technol. 683208

[4] Maity J, Jacob C and Singh R P 2014 Def. Sci. J. 64230

[5] Karger-Kocsis J, Mahmood H and Pegoretti A 2015 Prog. Mater. Sci. 731

[6] Mohsen N M and Craxg R G 1995 J. Oral Rehabil. 22213

[7] Yue C Y, Looi H C and Quek M Y 1995 Int. J. Adhes. Adhes. 1573

[8] Ai T, Wang R and Zhou W 2007 Polym. Compos. 28412

[9] Yong V and Thomas Hahn H 2004 SAMPE Conference Proceedings, $\mathrm{p} 49$

[10] Cheng Z, Li B, Huang J, Chen T, Liu Y, Xu W et al 2016 Mater. Des. 106216

[11] Oromiehie A, Ebadi-Dehaghani H and Mirbagheri S 2014 Int. J. Chem. Eng. Appl. 5117

[12] Zinck P and Gérard J-F 2008 Compos. Sci. Technol. 682028

[13] Jia C, Chen P, Liu W, Li B and Wang Q 2011 Appl. Surf. Sci. 2574165

[14] Sheu G S and Shyu S S 1994 Compos. Sci. Technol. 52489

[15] Wang C X, Du M, Lv J C, Zhou Q Q, Ren Y, Liu G L et al 2015 Appl. Surf. Sci. 349333

[16] Lim J S, Lee B H, Lee C B and Han I 2011 Compos. Interfaces 18323

[17] Xi M, Li Y-L, Shang S-Y, Li D-H, Yin Y-X and Dai X-Y 2008 Surf. Coat. Technol. 2026029

[18] Drescher P, Thomas M, Borris J, Riedel U and Arlt C 2013 Compos. Sci. Technol. 7460

[19] Jang B Z 1992 Compos. Sci. Technol. 44333

[20] Inagaki N, Tasaka S and Kawai H 1992 J. Adhes. Sci. Technol. 6279

[21] Cho D L, Claesson P M, Golander C-G and Johansson K 1990 J. Appl. Polym. Sci. 411373
[22] Zhang Y, Huang Y and He J 2008 Compos. Interfaces 15 611

[23] Fu S, Yu B, Duan L, Bai H, Chen F, Wang K et al 2015 Compos. Sci. Technol. 10823

[24] Yahaya R, Sapuan S M, Jawaid M, Leman Z and Zainudin E S 2015 Mater. Des. 67173

[25] Chatzi E G, Tidrick S L and Koenig J L 1988 J. Polym. Sci., B Polym. Phys. 261585

[26] Kim J G, Choi I, Lee D G and Seo I S 2011Comp. Structures 932696

[27] Liu N, Wang J, Chen B, Han G and Yan F 2014 Mater. Des. 55 805

[28] Wu J and Cheng X H 2006 Tribol. Lett. 24195

[29] Liu T-M, Zheng Y-S and Hu J 2011 Polym. Bull. 66259

[30] Mckelvey J B, Benerito R R, Bersi R J and Burgis B G 1963 J. Appl. Polym. Sci. 71371

[31] Manjunatha C M, Taylor A C, Kinloch A J and Sprenger S 2010 Compos. Sci. Technol. 70193

[32] Dueramae I, Jubsilp C, Takeichi T and Rimdusit S 2014 Compos. B 56197

[33] Scholz S, Kroll L and Schettler F 2014 Progress Org. Coat. 77 1129

[34] Chen J, Zhu Y, Ni Q, Fu Y and Fu X 2014 Appl. Surf. Sci. 321 103

[35] Singh T J and Samanta S 2015 Mater. Today Proc. 21381

[36] Wan Y Z, Lian J J, Huang Y, Wang Y L and Chen G C 2006 Mater. Sci. Eng. A $\mathbf{4 2 9} 304$

[37] Jia Z 2013 Fibers Polym. 1459

[38] Park S-J and Jin J-S 2001 J. Colloid Interface Sci. 242174

[39] Xing L, Liu L, Huang Y, Jiang D, Jiang B et al 2015 Compos. $B 6950$

[40] Rajkumar S, Tjong J, Nayak S K and Sain M 2015 J. Reinf. Plast. Compos. 34807

[41] Chu Y, Chen X, Wang Q and Cui S 2014 Appl. Surf. Sci. 320 710

[42] Kong H, Teng C, Liu X, Zhou J, Zhong H et al 2014 R. Soc. Chem. 420599 